\title{
Analysis of Changes in Awareness and Attitude Toward Hearing-Impaired Students by Experiencing Handicap in College Students
}

\author{
Woojae Han ${ }^{1,2,3}$, Minki Hong ${ }^{2}$, Taeoh Kim², Sihun Park ${ }^{1,2}$ \\ ${ }^{1}$ Laboratory of Hearing and Technology, ${ }^{2}$ Division of Speech Pathology and Audiology, ${ }^{3}$ Research Institute of Audiology and Speech Pathology, \\ College of Natural Sciences, Hallym University, Chuncheon, Korea
}

\author{
Received: March 3, 2020 \\ Revised: March 24, 2020 \\ Accepted: March 24, 2020 \\ Correspondence: \\ Woojae Han, PhD \\ Laboratory of Hearing and Technology, \\ Division of Speech Pathology and \\ Audiology, College of Natural Sciences, \\ 8603 Natural Science Building, \\ Hallym University, \\ 1 Hallymdaehak-gil, \\ Chuncheon 24252, Korea \\ Tel: +82-33-248-2216 \\ Fax: +82-33-256-3420 \\ E-mail: woojaehan@hallym.ac.kr
}

Purpose: The purpose of this study was to compare change in the perception of hearing impairment before and after the handicap experience and to qualitatively analyze accepting attitude and change toward the impairment in college students. Methods: Twenty college students were asked to wear personalized earplugs on their ears to experience the handicap of hearing loss for five days. They reported 12-items questionnaire before and after the experience and had also 1:1 individual interview using a structured format with open questions. Results: Although the negative attitude toward the hearing impairment (78.30\%) was high enough before the handicap experience, the positive attitude $(78.02 \%)$ was prominent after the experience. Further, the participants had expressed negative feeling such as guilt and avoidance toward the hearing impairment before the experience, while showing discrepancies between their cognition and behaviors. However, their perception and attitude were changed with positive recognition after the experience. Conclusion: Although it was a short period of the experience, the present results confirmed that the non-disabled students had an internal understanding and distracted negative attitudes toward the hearing impairment. The systematic and detailed handicap experiences might be expected to maintain a positive attitude toward the students with disabilities for a while.

Key Words: Attitude change, Awareness of the disabled, Handicap experience, Hearing loss, Qualitative study.

\section{INTRODUCTION}

장애(handicap or disabled) 자체에 초점을 두었던 과거와 달 리, 최근에는 장애인이 사회에서 도전자로 살아가고 있다는 의 미로 'challenged person' 혹은 비장애인과는 다른 능력을 가졌 다는 의미로 'differently abled person'으로 표현하는 등 장애인 들에 대한 시선이 긍정적으로 변화되고 있다(Bae et al., 2009). 그럼에도 불구하고 장애인에 대한 비장애인들의 태도는 여전히 표면적으로만 호의적일 뿐 현실에서는 그렇지 않다(Kastner et al., 1979). 이는 대중들이 겉으로는 장애인 취업을 찬성하면서 도 실질적으로 자신의 일로 적용될 때 장애인 고용을 기피하는 이중적인 행동을 보이는 것과 같다(Kim, 2002b; Kim \& Seo, 2004). 이러한 문제를 해결하기 위해선 장애인을 동등한 사회

(c) This is an Open Access article distributed under the terms of the Creative Commons Attribution Non-Commercial License (https://creativecommons.org/licenses/by-nc/4.0) which permits unrestricted non-commercial use, distribution, and reproduction in any medium, provided the original work is properly cited.
구성원으로 인정하지 않는 비장애인들의 인식 변화가 선행되어 야 한다(Shin, 2013).

한편, 인식이란 우리의 행동에 영향을 미치는 태도를 결정하 는 구성 요소로서 새로운 환경이나 사람과의 상호작용을 통해 형성되며, 형성된 각 개인의 인식은 태도에 영향을 미쳐 다시 사 회적인 행동으로 표출된다(Lee, 2005). 장애에 대한 인식의 변 화와 관련된 다수의 기존 연구들은 주로 장애에 대한 편견이 고 착화되기 이전의 시기인 영·유아 및 초등학생을 대상으로 프로 그램을 적용시켜 왔다(Bang \& Jean, 2007; Lim et al., 2013). 이 는 유아기에 장애에 대한 현실적인 인식과 태도를 형성시켜 주는 것이 시기적으로 중요하기 때문으로 설명될 수 있으나(Lim et al., 2013), 이중적 태도를 취하는 것은 오히려 유아기나 초등학 교 저학년 시기가 아니라 나와 다름이 충분히 인지되는 지적 능력을 갖고 사회 안에서 장애인이 약자라는 인식이 형성되었 을 때 시작된다는 주장이 설득력을 얻었다(Lee \& Lee, 2013). 다시 말해 장애인에 관한 인식과 수용 태도의 변화를 탐색하기 
위해서는 인식이라는 것이 형성되는 유아기도 중요하지만, 사회 의 구성원으로 살아가기 전 자신의 인식과 신념을 충분히 바꿀 수 있는 유연성을 지닌 초기 성년기에서의 연구가 필요하다 (Kim, 2002a). 비장애 대학생들에게 있어서 대학은 장애 학생 과 함께 생활하면서 자신의 장애 수용 범위를 자연스럽게 깨닫 게 되는 시간이며, 같은 맥락에서 장애 학생들에게는 비장애 학생들과 어울리면서 어떤 것을 체험했느냐가 대학을 졸업하고 사회에 자발적으로 나올 수 있는 동기를 제공받는 시간이다. 따 라서 대학생들이 장애 체험 활동을 하면서 장애 학우에 대한 인식의 변화가 어떻게 이뤄지고 있는지에 대한 탐색은 매우 중 요한 의미를 가진다.

Handlers \& Austin(1980)은 장애인에 대한 인식과 태도의 변 화에 가장 효과적인 방법은 장애인과 직접적인 접촉을 하거나 해당 장애의 어려움을 체험하는 것이라 하였고, Clore \& Jeffery(1972)의 연구에서는 휠체어를 타면서 자기 자신이 마치 장 애를 갖은 것처럼 행동하거나 눈가리개를 하고 지팡이를 짚고 길을 걸어보는 등 직접적 체험을 통해 장애에 대한 기존 인식 및 태도를 변화시킬 수 있었다. 실제로 이러한 장애 체험 프로 그램은 국내의 장애인 관련 기관 및 단체에서도 종종 실시되고 있지만, 안타깝게도 청각장애 체험 활동을 통한 비장애인의 인 식 및 태도의 변화를 살펴본 연구는 거의 전무하다. 따라서 본 연구에서는 청각장애 학생의 대학 생활을 비장애인 대학생들 이 대리 경험함으로써 체험 전후의 청각장애에 대한 인식을 비 교하는 것은 물론, 장애에 대한 수용 태도 및 변화를 인터뷰의 질적 분석을 활용하여 현상학적 접근으로 이해하고자 한다. 이 는 비장애 대학생들의 장애 체험이 그들의 삶에 끼친 청각 장 애우에 대한 인식과 수용 태도에 관한 의미와 본질을 살펴봄으 로써 궁극적으로는 사회 통합을 지향하는 우리의 장애 교육 전 반에 대한 논의점을 모색해 볼 수 있는 계기가 될 것이다.

\section{MATERIALS AND METHODS}

\section{연구 대상}

본 연구는 대학 재학생 남녀 각각 10 명씩 총 20 명을 대상으 로 진행하였다. 체험에 관한 현상학적 연구를 실시함에 있어서 연구 참여자 수의 타당성 확보는 Dukes(1984)에 의하여 권고 된 3 10명 전후를 만족하였기에, 이에 해당하는 인원수로 성비
를 고려하여 선정하였다.

연구 대상자의 모집은 이미 청각 장애인에 대한 기초 지식과 배 려가 있는 언어청각학, 사회복지학, 간호학을 전공하는 학생들을 배제하고, 현재 한림대학교 재학생들 중 자발적으로 연구 참여를 희망하는 대상자들에게 본 연구의 목적 및 절차를 설명한 후 연 구동의서에 서명하도록 하였다.

\section{측정 도구}

본 연구에서는 장애 체험을 경험하기 이전과 이후의 체험자의 태도 변화를 12개의 태도 유목으로 분류한 Kim(2002a)의 범주 를 활용하여 체험 전과 후에 각각 한 번씩 설문(Appendix 1)을 실시한 후 변화 정도를 비교하였다. 또한 Cheong \& Jo(2016)의 질적 연구에서 사용한 설문 문항들을 청각장애 특성에 맞게 재구성하여 5 일간의 청각장애 체험 후 30 분에서 약 1 시간 정도 의 1:1 심층 면담을 실시하였다. 즉, 연구 대상자의 장애 체험이 충분히 반영될 수 있도록 반 구조화된 질문지(Appendix 2) 내 에 자유롭게 이야기할 수 있는 개방형 질문을 추가적으로 실시 하였다.

측정 장소는 연구 참여자가 조용하고 편안하게 이야기할 수 있고 비밀 보장이 이루어질 수 있는 곳에서 진행하였다. 연구자 는 인터뷰 과정에서 연구 참여자의 비언어적인 행동이나 주요 특징에 대하여 메모하며 이를 분석에 추가하였다.

\section{모의 청력 손실}

먼저 설문지를 작성한 후 20명의 연구 대상자들에게 125 $8,000 \mathrm{~Hz}$ 의 어음 주파수 범위에서 음장검사를 실시하여 주파수 별 역치를 기록하였다. 이때 각 주파수별로 $15 \mathrm{~dB} \mathrm{HL}$ 이하의 소 리에서 들었다고 반응하는 연구 대상자만 실험에 참여하였다.

청각장애 체험을 위해 각 연구 대상자의 개인용 맞춤 귓본을 제작하였다. 즉, 시중에서 판매하는 획일적인 크기의 이어플러 그와 달리 인체에 무해한 맞춤형 귓본을 제작하고 착용함으로 써 외부로부터 일정 정도의 소리를 효율적으로 감쇄시켜 전음 성 난청의 청각장애인 시뮬레이션 환경을 구축하였다. 연구 대 상자는 귓본을 착용한 상태에서 음장검사를 재실시하여 제시 되는 자극음이 일정 정도 차단되었는지 감소량을 확인한 후 체 험을 시작하였다. Table 1 은 귓본 착용 전과 후의 연구 대상자 20 명의 평균 청력을 제시하였다. 주파수별로 감소량에 차이가

Table 1. Group mean and standard deviation for comparison of the $\mathrm{dB} H \mathrm{HL}$ between unblocked and blocked conditions while being presented by a speaker in the sound-field

\begin{tabular}{lrrrrrr}
\hline Condition & \multicolumn{5}{c}{ Hearing threshold in frequency $(\mathrm{Hz})$} \\
\cline { 2 - 7 }$(\mathrm{dB}$ HL) & \multicolumn{1}{c}{250} & \multicolumn{1}{c}{1,000} & \multicolumn{1}{c}{2,000} & \multicolumn{1}{c}{4,000} & 8,000 \\
\hline Unblocked & $3.25 \pm 3.35$ & $4.25 \pm 1.83$ & $3.75 \pm 4.55$ & $4.05 \pm 1.25$ & $5.75 \pm 3.35$ & $4.85 \pm 4.22$ \\
Blocked & $37.00 \pm 2.99$ & $32.50 \pm 2.56$ & $33.50 \pm 4.01$ & $30.00 \pm 9.87$ & $33.00 \pm 5.48$ & $39.20 \pm 4.83$ \\
\hline
\end{tabular}

dB HL: hearing levels in decibels 
있었으나, 착용으로 인해 전반적으로 약 $30 ~ 35 \mathrm{~dB} \mathrm{HL}$ 정도의 일시적 청력 손실이 발생하였다.

\section{청각장애 체험}

장애인에 대한 긍정적인 태도 변화를 갖도록 하기 위해서 필요 한 최적의 봉사 활동 시간은 10 20시간 정도로 권장된다(Kim, 2002a). 따라서 태도 변화가 충분히 반영될 수 있도록 본 연구 에서는 연구 대상자들에게 하루 2 시간씩 5 일간 총 10 시간 동안 청각장애를 체험하도록 요구하였다. 체험 기간 동안 대학생들 이 학내에서 가장 빈번하게 하는 일상 활동들 중 7 가지를 활용 하여, 예를 들어 수업 10 분 일찍 가서 강의실에서 수업 시작 전 까지 귓본 착용하기, 귓본 착용 후 휴대전화 혹은 컴퓨터를 사 용하여 30 분 이상 인터넷 강의 시청하기, 귓본 착용 후 캠퍼스 벤치에 30 분간 앉아 있기, 귓본 착용 후 친구들과 팀 과제 30 분 이상 진행하기, 대중교통 탑승 후 귓본을 착용하여 목적지 에 도착하기, 귓본 착용 후 카페 혹은 학생식당에서 메뉴 주문 해 보기, 귓본 착용 후 친한 친구와 20분 이상 전화 통화하기 등을 수차례 경험하고, 해당 체험 활동을 인증 사진으로 찍으 며 그때그때의 감정이나 불편한 점을 기록하도록 요청하였다.

\section{데이터 및 통계 분석}

본 연구에서는 단순 빈도 분석과 카이제곱검정을 통한 교차 분석을 SPSS 통계프로그램(Ver. 21, IBM Corp., Armonk, $\mathrm{NY}, \mathrm{USA}$ )을 이용하여 유의 수준 $p<0.05$ 에서 분석하였다.

또한 대학생들의 기존의 장애 인식을 분석하고, 장애 체험을 하면서 변화된 장애 인식 및 수용을 van Manen(1990)의 현상 학적 연구 방법을 활용하여 체험 연구 분석의 4 가지 단계(전체 인식 단계, 의미 단위 규명, 주제어의 학문적 용어 변경, 구성 요소 도출)로 변형한 후 적용하였다(Tuohy et al., 2013). 구체적 으로 녹음된 자료를 연구자의 지식과 편견을 배제하며 수차례 청취하여 대상자의 진술이 내포하는 전반적인 느낌을 얻은 후, 체험자의 언어 그대로 자신의 장애 경험을 표현한 기술의 단위 를 중심으로 전사된 자료의 의미를 규명하였다. 이를 위해 대상 자의 진술 가운데 의미 전환이 일어나는 부분을 사선으로 구 분하고 각각의 의미 단위 앞에 번호를 매겼다. 또한 나누어진 의미 단위를 조합하여 주제화하고 주제 안에 내포된 중심 의미 를 학문적 용어로 변경시킨 후, 상황적 구조를 기술하고 각 구 성 요소들 간의 상관관계를 내포하고 있는 경험의 일반적 구조 로 기술하여 기존의 장애 인식, 태도, 행동들이 장애 체험의 활 동을 통하여 어떻게 변화되고 장애 수용에 어떤 의미를 제공했 는지 분석하였다(Cheong \& Jo, 2016).

이 모든 과정은 질적 연구를 전공한 사회복지학 교수와 심리 학 교수에게 연구 방법과 분석 과정에 대한 2차례의 감수를 통
해 분석 내용의 의미 기술 적합성을 검증받았다.

\section{RESULTS}

\section{장애 체험 전후의 태도 변화}

청각장애 체험 이전의 청각 장애인에 대한 대학생들의 초기 태도 설문 결과를 분석하여 Table 2에 요약하였다. 초기 태도 중 부정적인 태도는 $78.30 \%$, 중성적 태도는 $20.75 \%$, 긍정적 태 도는 $0.94 \%$ 로 각각 나타났다. 그중 높은 응답률을 보인 부정적 태도를 구체적으로 살펴보면 20명의 응답자 중 19명(17.92\%)이 청각장애인에 대해 '거리감 혹은 이질감'을 느낀다고 답변하였 고, 16명(15.09\%)의 응답자는 청각장애인에 대하여 ‘답답하고 어 렵다라고 표현하였다. 중성적인 태도 중 청각장애인이 '낮설다'는 응답도 15명(14.15\%)으로 다소 높게 분석되었다. 청각 장애인에 대한 초기 태도는 성별에 따라 크게 다르지 않았다.

청각장애 체험 이후의 태도 변화는 Table 3에서 볼 수 있듯 이 긍정적 태도는 $78.02 \%$, 중성적 태도는 $21.98 \%$ 였다. 가장 강 한 긍정적인 태도라고 할 수 있는 청각 장애인과 '함께하고 싶 음은 20명의 체험자들 중 19명(10.44\%)이 응답하였고, 체험 후 ‘편견 및 선입견이 불식'되었거나, 청각장애인과 ‘친구가 되고 싶 고', '동정심이 생기는, '도움이 필요한 대상'으로 여겨진다고 응 답한 대상자는 각각 17 명 $(9.34 \%)$ 으로 5 일간의 장애 체험으로 긍정적인 변화를 나타내었다. 더불어 청각장애 체험이 '올바른 인식을 하게 된 기회'가 되었고, '스스로 반성의 계기가 되었다' 는 중성적 태도는 응답자 20명 모두에게서 동의를 얻었다. 체험 이전의 초기 태도들과 비슷하게 체험 후 긍정적 태도와 중성적 태도에서도 성별에 따른 응답자 간 특징은 두드러지지 않았다.

청각장애 체험에 따른 경험 후 태도 변화 간의 질적 변수들의 관계를 분석한 카이제곱검정의 결과는 $\chi^{2}=4.079, p=0.003$ 으 로 통계적으로 유의하게 나타났다. 즉, 5 일간의 청각장애 체험 이 연구 대상자들에게 체험 후 태도 변화에 의미 있는 영향을 끼쳤다.

\section{체험 후 청각장애 수용 태도}

20 명의 연구 참여자들의 인터뷰를 분석하여 현상학적 방법 에 따라 청각장애 체험을 분류하였다. 심리학적 용어로 변환된 의미 단위들이 공통된 요소로 묶여 42 개의 의미로 요약되었고, 하위 구성 요소로는 회피적/위악적 태도, 정서, 인지 부조화, 적 극적/위선적 태도, 긍정/부정적 감정, 인지 조화, 교육 요구의 7 개로 추출하였다(Cheong \& Jo, 2016). 다시 하위 구성 요소들은 동질성을 갖는 구성 요소로서 '체험 이전의 청각장애에 대한 인 식과 태도', '체험 이후의 청각장애에 대한 인식과 태도', '청각장 애 수용 태도의 변화와 통찰'의 총 3개로 구조화되었다. 


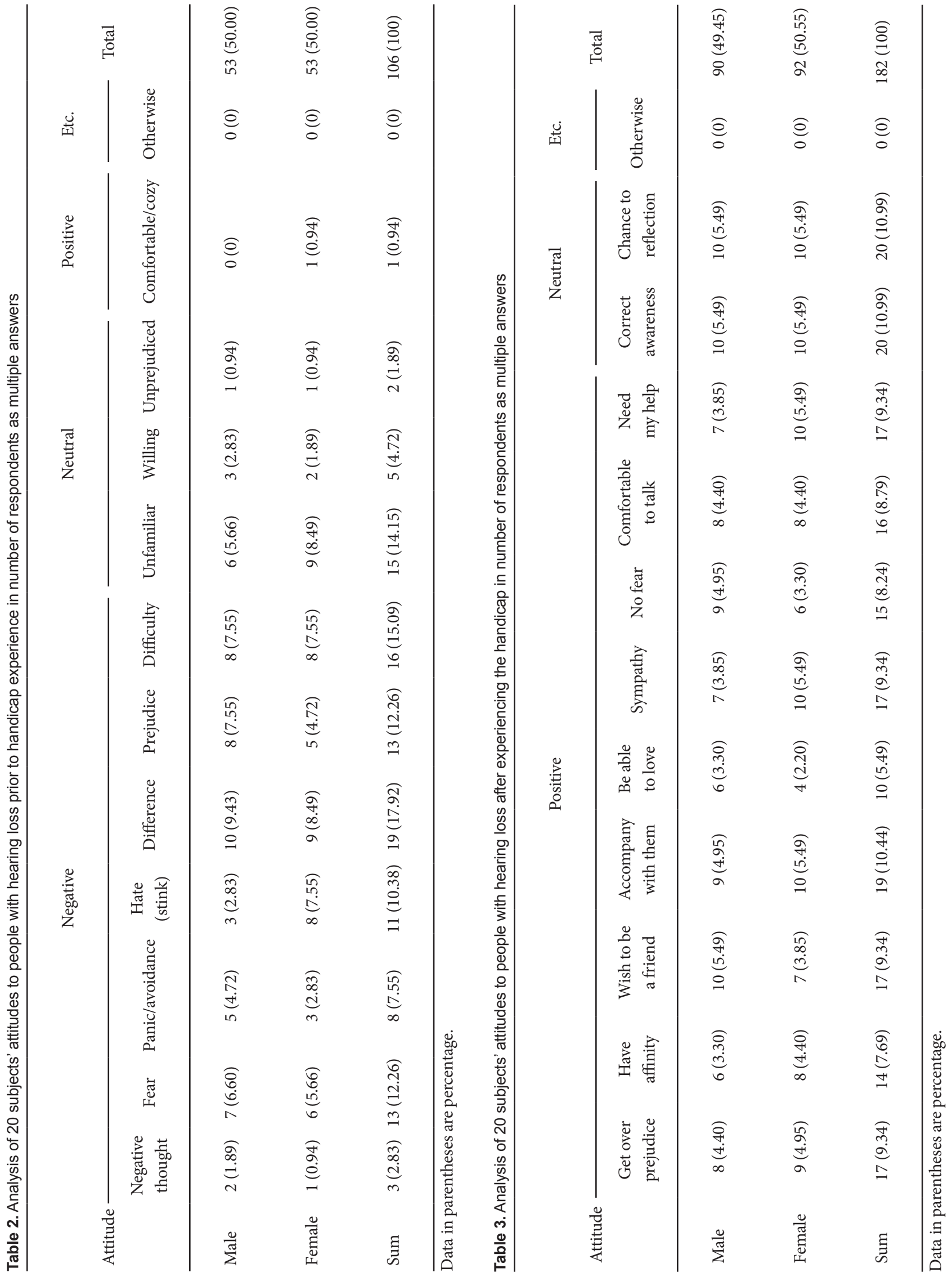


Table 4는 체험 전 청각장애인에게 평소 갖고 있던 인식에 관 한 인터뷰 내용을 분석 요약하였다. 때때로 학교 내에서 청각장 애 학우와의 접촉은 연구 대상자들에게 공통적으로 '죄책감', '미안함', ‘불편함' 등의 정서적 감정을 갖게 하였으나, 행동적으 로는 '회피적 태도'를 표현하였다. 즉, 그동안 공교육 등을 통하 여 비장애 대학생들은 장애인 혹은 장애 학우를 생각할 때 '도 와주어야 하거나, '도움이 필요한 사람'이라고 배워왔으나, 불편 한 상황을 회피하고자 하는 즉흥적인 행동을 표출하며 '무언가 할 일을 제대로 못하고 있다'는 인지와 행동 간의 불일치를 경 험하고 있는 것으로 분석되었다.

청각장애 체험 후 인터뷰 내용을 분석한 것은 Table 5에 요약 하였다. 태도의 측면에서 '적극적'이나 ‘위선적' 태도, 정서적 측 면에서는 ‘긍정'과 ‘부정’ 정서가 공존하였고, 인지적 측면에서는 태도와 정서 간 조화롭고자 노력하였다. 흥미로운 의미 단위는 "장애가 피해 의식이나 특권 의식이 아니다"는 것을 통하여 학 내에서 웅크려 있는 장애 학생에 대한 거리를 없애고자 하는 인
지적 표출을 드러냈다. 또한 장애 체험을 통하여 '상대방에 대 하여 더 많이 이해'하고, ‘청각장애의 구체적인 어려움이 내면적 으로 받아들여졌다'는 인터뷰 내용은 전체 참여자 중 대다수를 차지하였다. 마지막으로, 장애 학생 및 비장애 학생 모두 장애 에 대한 지식을 올바르게 습득하여 장애 수용에 대한 변화와 통찰이 필요함을 제시하였다.

\section{DISCUSSIONS}

본 연구는 청각장애 체험을 통하여 일반 대학생들이 청각 장애 학우를 인식하고 수용하는 데에 어떠한 영향을 주었는지 그 의미를 양적·질적으로 탐색하였다.

예상대로 연구 대상자들의 초기 태도는 청각장애에 대하여 매우 부정적으로 나타났다. 이는 타인에 대한 의식이 강한 우리 사회가 나와의 '차이'를 ‘차별'의 대상으로 여김으로써 도와주어 야 하는 대상에서 배제시키는 경우에서 시작된다(Kim \& Seo,

Table 4. Analysis of 20 subjects' handicap acceptance attitudes to people with hearing loss before experiencing the hearing handicap

\begin{tabular}{lll}
\hline \multicolumn{1}{c}{ Category } & \multicolumn{1}{c}{ Subcategory } & \multicolumn{1}{c}{ Meaning Units } \\
\hline $\begin{array}{l}\text { Awareness and attitude before experiencing } \\
\text { the hearing handicap }\end{array}$ & Skeptical/malicious attitude & Avoid opportunity to meet \\
& & Return to see students with disabilities \\
& Even if I see teasing, I pass by \\
& It's not my job and I can't act \\
& Negative/neutral emotion & Discomfort, guilty, sorry \\
& & I didn't like them \\
& & Sometimes disgusting \\
& Suffering from discomfort feeling \\
& It's annoying just to see \\
& I learned not to discriminate them \\
\end{tabular}

Table 5. Analysis of 20 subjects' handicap acceptance attitudes to people with hearing loss after experiencing the hearing handicap

\begin{tabular}{|c|c|c|}
\hline Category & Subcategory & Meaning Units \\
\hline \multirow{11}{*}{$\begin{array}{l}\text { Awareness and attitude after } \\
\text { experiencing the hearing handicap }\end{array}$} & Positive/hypocritical attitude & First come help \\
\hline & & Wait to speak first \\
\hline & & Try to solve any misunderstandings \\
\hline & & Feel comfortable to laugh with them \\
\hline & Neutral/positive emotion & I opened my heart \\
\hline & & Crying \\
\hline & & Ready to be hurt \\
\hline & & Angry / I feel uncomfortable \\
\hline & Recognition and harmony & I just did as I learned \\
\hline & & I was happy and talked as I wanted to \\
\hline & & E.g., "You're feeling hurt.", "You're privileged." \\
\hline \multirow{2}{*}{$\begin{array}{l}\text { Changes and insights into disability } \\
\text { acceptance }\end{array}$} & Education need & All students with disabilities and non-disabilities need education \\
\hline & & Students with disabilities want to educate themselves \\
\hline
\end{tabular}


2004). 그럼에도 $\mathrm{Kim}(2002 b)$ 과 Lee \& Lee(2013)의 연구에 의 하면 장애 접촉 빈도가 높은 학생들은 장애인을 수용하는 태 도가 매우 긍정적임을 고려한다면, 장애에 대한 사회의 부정적 인식이 고착되기 이전에 긍정적 수용 태도로 변화할 필요가 있 으며 사회·제도적 측면에서 표면적으로 나타나는 장애 수용 태도의 이중적 인식을 감소시킬 수 있다는 점에서 본 연구의 체험자들의 결과는 의미 있게 해석할 수 있다.

선행연구의 결과와 동일하게 본 연구의 양적 및 질적 분석 결 과 또한 동일하게 일반 대학생의 장애에 대한 기존 인식이 청각 장애 체험을 통해 장애 학생을 대하는 태도와 행동에 긍정적 인 영향을 주었다(Bae et al., 2009). 또한 장애 인식에 있어서 '장애인들에게 실질적인 도움을 주어야' 하며 '차별하지 않는 행동을 해야 한다'고 변화되었다. 이는 기존의 다른 장애군의 선행연구들과 동일하게 나타났다(Kim, 2002a; Kim, 2002b; Lee, 2015). 그러나 장애 접촉 빈도의 양적 증가가 장애 수용 태도를 긍정적으로 변화시키지 않는다는 선행연구들을 통하여 장애인과 비장애인의 접촉 유형과 질적인 부분이 어떻게 장애 수용 태도에 영향을 주는지에 대한 좀 더 깊은 탐색이 필요할 것으로 보인다. 특히 작위적인 실험 환경에서 보여주는 장애 수 용 태도와 자율적 교육 환경에서 학생들 스스로가 선택하여 장애에 대한 인식과 수용적 측면의 변화가 이뤄지는 현상에 대 한 비교연구를 통하여 의미 있는 분석이 뒤따라야 할 것이다.

본 연구를 진행하는 데 있어 구체적인 제한점은 다음과 같다. 첫째, 강원도 춘천시에 위치한 대학생들을 연구 대상자로 하여 진행한 실험이기에 본 연구의 결과는 문화 혹은 환경이 다소 상이한 국내의 전체적인 인식으로 일반화하여 해석하기에는 한 계점이 있다. 둘째, 맞춤형 귓본의 착용으로 연구 대상자들의 청력 손실은 전음성 난청만 발생 가능하였다. 즉, 연구 대상자 들의 외이도만 차단할 수 있기 때문에 골도로 전달되는 소리는 차단하는 데 한계가 있었고, 결과적으로 청각장애인들이 느끼 는 소리의 감쇄 및 왜곡 현상보다는 연구 대상자들은 귓본 착 용으로 소리가 울리거나 다소 답답하게 느껴질 수 있었다. 셋 째, 본 연구에서는 약 $30 \mathrm{~dB}$ HL의 난청을 발생하였기에 중도 이상의 난청 정도를 경험하지 못했다. 마지막으로 장애 인식의 변화가 단기간에 체험자들의 장애 수용 태도에 영향을 미칠 수 있음을 결과적으로 보여주었지만, 그 영향이 장기간 지속력을 가질 수 있는지 확신하기 어렵다(Kim, 2002a). 또한 체험을 하 지 않은 대조군과의 직접적 비교가 없었기에 장애 인식의 변화 정도를 그대로 해석하기에는 한계가 있다. 따라서 장애 수용 태 도와 인식의 변화 및 변화 정도가 향후 청각장애에 대한 이미 지와 이해에 끼치는 지속력에 대하여서는 후속연구에서 언급 되어야 하겠다.

1995년부터 국내에서는 특수교육 대상자들의 대학 입학 특
별전형제를 시작하여 장애인들의 고등교육 기회 확대와 장애인 에 대한 인식 개선 및 이들의 사회적 지위를 향상시켜 준다는 점에서 많은 관심을 받아왔다(Cheong \& Jo, 2016). 즉 비장애 학생들과 비교해 볼 때 교육과정 운영의 특성이나 평가 도구 및 방법의 제한으로 인해 대학 진학의 기회가 상대적으로 불리하 였던 장애 학생들에게 그에 상응한 차등적인 교육적 보상 기준 을 적용함으로써 교육의 기회 균등을 실질적으로 보장해 준 제 도라 할 수 있다. 따라서 지금까지 특수교육 대상자들의 대학 입 학 특별전형제의 실시는 소외되었던 많은 장애인들에게 고등교 육 기회를 확대시켜 주었다는 긍정적인 결과를 이끌었다. 하지 만 그 이면에는 장애 대학생들이 대학에서 기본적인 생활 및 학 업 수행에 많은 어려움을 겪고 있을 뿐만 아니라 어려움으로 인 해 학업을 포기하는 경우도 늘어나고 있다(Bae et al., 2009). 소 소하게는 비장애 학생들의 위선적인 행동이 장애 학생과의 오해 를 만들거나 혹은 지속적인 의사소통의 단절 등으로 인하여 서 로에 대한 상처를 남기고, 이는 장애 학생들이 올바른 사회 생 활을 지향하기에 고립과 한계를 경험하게 한다. 따라서 향후 비 장애 학생들이 보다 세밀하고 구체적인 각 장애별 한계들을 직 간접적으로 체험하고 그 한계점을 있는 그대로 배우는 것에 초 점을 맞추어야 하겠다(Lee, 2015). 이러한 부분은 본 연구의 결 과 마지막 부분에서도 드러난 대로, 비장애 학생들이 청각장애 학우들에 대한 실질적인 교육과 청각장애 학생들이 비장애 학 우들에게 어려움을 그대로 알려주는 양방향 소통이 이어진다면 물리적·제도적 차원으로 해결되지 않는 여러 문제들을 극복하 고 장애인을 동등한 사회 구성원으로 인정하는 사회 풍토가 대 학에서부터 시작되고 정착될 수 있을 것이라 기대한다.

중심 단어 : 태도 변화·장애에 대한 인식·장애 체험·청력 손실· 질적 연구.

\section{Ethical Statement}

This study was approved by the Institutional Review Board of Hallym University (HIRB-2019-082).

\section{Acknowledgments N/A}

\section{Declaration of Conflicting Interests}

There are no conflict of interests.

\section{Funding}

This work was supported by the Hallym University Research Fund (HRF-202002-012) and the Ministry of Education of the Republic of Korea and the National Research Foundation of Korea (NRF-2018S1A3 A2074932).

\section{Author Contributions}

The authors discussed the results altogether and implications while commenting on the manuscript at each stage. In detail, W.H. and M.H. designed performed experiments, M.H. and T.K. collected data, and S.P. 
and W.H. analyzed data. Also, W.H. wrote the paper and reviewed it as the corresponding author.

\section{ORCID iD}

Woojae Han

https://orcid.org/0000-0003-1623-9676

\section{REFERENCES}

Bae, H. B., Oh, W. S., \& Lee, Y. M. (2009). A study on the disability perception of college students according to the types of disabilities. The Journal of Elementary Special Education, 11(1), 83-104.

Bang, M. \& Jean, S. (2007). Impact of a role-play centered program on the self-determination skills of children with disability and the emotional competence and attitudes of nondisabled children toward children with disabilities. Korean Journal of Early Childhood Special Education, 7(1), 157-173.

Cheong, M. J. \& Jo, H. (2016). Before and after the challenged acceptance attitude of students who participated in the challenged students support program in college. Korean Journal of Youth Studies, 23(12), 209244.

Clore, G. L. \& Jeffery, K. M. (1972). Emotional role playing, attitude change, and attraction toward a disabled person. Journal of Personality and Social Psychology, 23(1), 105-111.

Dukes, S. (1984). Phenomenological methodology in the human sciences. Journal of Religion and Health, 23(3), 197-203.

Handlers, A. \& Austin, K. (1980). Improving attitudes of high school students toward their handicapped peers. Exceptional Children, 47(3), 228229.

Kastner, L. S., Reppucci, N. D., \& Pezzoli, J. J. (1979). Assessing community attitudes toward mentally retarded persons. American Journal of Mental Deficiency, 84(2), 137-144.
Kim, C. N. \& Seo, M. K. (2004). A study on prejudice and discrimination against the mentally ill. The Korean Journal of Health Psychology, 9(3), 589-607.

Kim, J. B. (2002a). Effects of youth volunteering on the attitude change towards the handicapped. Studies on Korean Youth, 13(1), 133-173.

Kim, M. (2002b). A study on social distance on people with disability. Mental Health and Social Work, 14(1), 99-126.

Lee, E. H. (2015). The influence of university students' contact experience with the disabled on their perception of the disabled (Unpublished master's thesis). Korea National University of Transportation, Chungju.

Lee, H. W. \& Lee, M. H. (2013). Impact of mood awareness, emotional expressiveness, and ambivalence over expressing emotion of college students on self-efficacy. Journal of Emotional and Behavioral Disorders, 29(3), 181-200.

Lee, I. J. (2005). An explorative study on the application of theories of attitudes and attitude change in social work practice. Korean Journal of Social Welfare Studies, 28, 105- 131.

Lim, Y. S., Jeon, S. H., \& Ryu, G. D. (2013). Effect of improvement of disability awareness program on attitudes of accepting disability of general children. Journal of Children's Literature and Education, 14(4), 691-709.

Shin, M. S. (2013). A study on the handicapped employment and social integration policy in centered with Korea and Swedish institutional comparison. Journal of Association for Korean Public Administration History, 32, 161-192.

Tuohy, D., Cooney, A., Dowling, M., Murphy, K., \& Sixsmith, J. (2013). An overview of interpretive phenomenology as a research methodology. Nurse Researcher, 20(6), 17-20.

van Manen, M. (1990) Researching Lived Experience: Human Science for an Action Sensitive Pedagogy. Albany, NY: State University of New York Press. 


\section{APPENDICES}

\section{Appendix 1. 대학생의 청각장애 체험 활동 전후의 장애 태도 범주}

1. 청각장애 체험 전의 장애인에 대한 태도 (해당 사항을 모두 번호 앞에 체크하시오. 중복 가능)

(1) 장애인의 삶 자체를 부정적으로 생각했다.

(2) 장애인이 두렵거나 무서웠다.

(3) 장애인을 보고 당황하여 기피하고 싶었다.

(4) 장애인에게서 이상한 냄새가 나서 싫었거나 피했다.

(5) 장애인에 대한 거리감과 이질감을 느꼈다.

(6) 장애인에 대한 나름대로 편견이나 선입견을 가지고 있었다.

(7) 장애인을 대하는 것이 답답하고 어려웠다.

(8) 장애인들이 낮설었다.

(9) 장애인에 대해 특별한 거부감은 없었다.

(10) 별다른 선입견이 없었다.

(11) 장애인들을 마음 편하게 해주고 싶었다.

(12) 기타 의견 (

2. 청각장애 체험 후의 장애인에 대한 태도 (해당 사항을 모두 번호 앞에 체크하시오. 중복 가능)

(1) 장애인에 대한 편견이나 선입견이 없어졌다.

(2) 장애인에게 친숙(친밀)감을 갖게 되었다.

(3) 외로운 장애인들에게 진실된 친구가 되거나 친동생같이 대하고 싶다.

(4) 체험 활동을 마친 후에도 조금 더 같이 있고 싶은 마음이 생긴다.

(5) 장애 아동을 사랑으로 대해줄 용기가 생겼다.

(6) 장애인이 불쌍하다는 생각을 많이 갖게 되었다.

(7) 장애인에 대한 두려움이 없어졌다.

(8) 장애인들에게 익숙해져 편하게 대할 수 있다.

(9) 장애인은 나의 도움이 조금 더 필요한 사람이다.

(10) 장애인도 정상인보다 더 올바른 생각을 가지고 있다는 것을 알게 되었다.

(11) 장애인의 재능과 능력, 의지를 보고 나의 태도와 생활을 되돌아보는 계기가 되었다.

(12) 기타 의견 


\section{Appendix 2. 면담 질문 목록}

\begin{tabular}{c|c}
\hline \multicolumn{1}{c|}{ 연구 문제 } & \multicolumn{1}{c}{ 세부 질문 } \\
\hline $\begin{array}{c}\text { 장애 체험 전에 갖고 있던 청각장애에 } \\
\text { 대한 태도는 어떠한가? }\end{array}$ & $\begin{array}{l}\text { (1) 대학을 들어오기 전 초·중·고 시절에 통합교육을 실시했는가? } \\
\text { (2) 대학을 들어오기 전 초·중·고 시절에 청각장애 학생과의 직접적 관계를 맺은 적이 } \\
\text { 있는가? } \\
\text { (3) 대학을 들어오기 전 초·중·고 시절에 청각장애에 대한 인식, 태도는 어떠했는가? }\end{array}$ \\
\hline $\begin{array}{c}\text { 청각장애 체험 활동 후 장애에 대한 } \\
\text { 태도는 어떻게 변화되었는가? }\end{array}$ & $\begin{array}{l}\text { (1) 청각장애 체험을 하게 된 계기는 무엇인가? } \\
\text { (3) 청각장애 체험을 하면서 장애에 대한 인식이나 태도, 행동에 변화가 있었는가? } \\
\text { 있었다면 무엇이 변화를 이끌었는가? }\end{array}$ \\
\hline $\begin{array}{c}\text { 청각장애 체험 후 청각장애인에 대한 } \\
\text { 태도 변화는 어떠한 의미인가? }\end{array}$ & $\begin{array}{l}\text { (1) 장애라는 것이 무슨 의미인가? 청각장애는 무슨 의미인가? } \\
\text { (2) 청각장애 체험 활동 후 (청각)장애인에 대한 의미는 무엇인가? }\end{array}$ \\
\hline
\end{tabular}

